\title{
Libro: El ascenso del Príncipe democrático. Quién gobierna y cómo se gobiernan las democracias
}

Sergio Fabbrini

Fondo de Cultura Económica, Buenos Aires, 2009 (275 pp.)

\section{Martín D'Alessandro}

Doctor en Ciencias Sociales (UBA), Profesor de Ciencia Política (UBA), Investigador del Conicet, Argentina.

E-mail: martindalessa@gmail.com

¿Cuáles son los motivos que favorecen el ascenso de los líderes políticos? Las respuestas de Fabbrini - profesor en las universidades de Trento y California (Berkeley) y director de la Rivista Italiana di Scienza Politica- van apareciendo a lo largo de este libro, versión traducida y actualizada de Il Principe democratico. Le leadership nelle democrazie contemporanee, de 1999. Fabbrini se limita a los líderes de los ejecutivos democráticos, excluyendo a los líderes que no ocupan el poder ejecutivo: asume, directamente, que quien llega al ejecutivo es ya un líder, o bien tiene muchas oportunidades de llegar a serlo, y con cuatro casos de estudio -Estados Unidos, Gran Bretaña, Italia y Francia- cubre gran parte de las formas de gobierno existentes. Los líderes son siempre necesarios, pero en las democracias actuales hay razones sistémicas y estructurales que acentúan su rol. El debate público debe evitar el decisionismo (el líder es el único que puede revitalizar a las democracias) tanto como el asamblearismo (el liderazgo sólo trae peligros). Una democracia es sólida si garantiza al mismo tiempo la toma de decisiones y el control (institucional) de quien las toma.

El libro se divide en tres partes. En la primera se desarrollan las dos perspectivas analíticas más comunes para el estudio del liderazgo político: la que vincula al líder con el sistema de gobierno y la que lo considera en el contexto de los medios de comunicación. El capítulo 1 se encarga de la primera, que considera al líder por la función que cumple en el sistema formalizado de la autoridad pública. Desde este punto de vista el liderazgo es la naturaleza de la acción decisional que realiza la persona investida de tal poder, en un contexto institucional y en un tiempo histórico determinados. Considerando la teoría del liderazgo en sentido amplio, este es el aporte conceptual más importante del libro, y es lo que permite su desarrollo posterior: los contextos institucionales (tales poderes y tales controles) favorecen o no determinados cursos de acción y modalidades de ejercer el liderazgo: los presidencialismos y semipresidencialismos entronan al ejecutivo, aunque fragmentan el poder; en los parlamentarismos competitivos hay una conducción explícita y el líder es un transformador del statu quo; y en los parlamentarismos consensuales hay coaliciones partidarias amplias y poco gobierno. Así, en los primeros hay una visión positiva del líder, que crea las condiciones para la movilización de los ciudadanos y de los grupos sociales excluidos de la política partidaria, y genera una 
responsabilidad política clara, pudiendo darle una voz a las difusas exigencias de cambio, y en los últimos hay una visión negativa: la elección directa del poder ejecutivo y su consecuente liderazgo personal pueden derivar en la verticalización plebiscitaria de los vínculos políticos.

El capítulo 2 se encarga de las transformaciones de la comunicación. Aquí hay dos aproximaciones: el "espectáculo político" en el que la ciudadanía pasiva recibe rituales y mensajes simbólicos que los medios presentan con ambigüedad, dramatización, simplificación y personalización (los medios identifican la acción política con la persona del líder), y el "mercado de las ideas", en el que las masas fueron ganando espacio en la opinión pública a través de la organización partidaria, incluso cuando los cambios tecnológicos de campaña corroyeron a los partidos. Ambas aproximaciones muestran a la personalización de la política como una consecuencia inevitable de las transformaciones culturales y tecnológicas. Pero aunque en la "democracia de audiencia" la política electoral es una actividad exclusiva del líder, la política gubernamental requiere modalidades colectivas de colaboración, es decir, coaliciones partidarias relativamente estables en los parlamentos (incluido el Congreso de Estados Unidos).

La segunda parte del libro compara las características del liderazgo a partir de factores internos en los países estudiados. El capítulo 3 analiza la relación entre los partidos y los candidatos presidenciales en Estados Unidos. Es apasionante la reconstrucción del debate politológico de casi cien años sobre el papel que los partidos debían ocupar en ese país, dadas sus características institucionales, económicas y culturales (descentralizados o cohesionados, participativos o competing teams con fuertes liderazgos). A pesar de las recomendaciones de la Asociación Americana de Ciencia Política, en los 70s se implementaron reformas que en realidad transformaron a los partidos en organizaciones de los candidatos más que en organizaciones para lograr un gobierno responsable. Sin embargo, a partir de los 90s el Partido Republicano fue centralizándose y fortaleciendo grupos congresionales, y en la década siguiente hubo un verdadero gobierno de partido.

El capítulo 4 muestra cómo en ese país -debido a cambios no constitucionales sino históricos, institucionales y partidarios- el gobierno presidencial sustituyó al gobierno congresual. Si durante el siglo XIX el presidente era un funcionario con el deber de salvaguardar la Constitución y de hacer cumplir las decisiones del legislativo, en el siglo XX surgió la presidencia moderna: Roosevelt hizo confluir la dimensión popular del cargo (la capacidad de movilizar a los ciudadanos y a la opinión pública) con la dimensión gubernamental (dirigir la presidencia y conseguir el apoyo de los congresistas del propio partido).

La radio y luego la televisión neutralizaron el tamaño del territorio y generaron la presidencia retórica, que funda su legitimación en la comunicación directa (no necesariamente demagógica) con los ciudadanos, y convierte a la presidencia en la representación del interés general y la unidad nacional. Roosevelt, un regime builder, introdujo y consolidó el refuerzo del gobierno federal frente a los gobiernos estaduales y frente al Congreso, la disminución del poder de los partidos y el fortalecimiento de la estructura burocrática del poder ejecutivo. Pero todos los presi- 
dentes posteriores fueron regime managers. Reagan intentó una independencia decisional frente al Congreso pero fracasó: la política de candidatos y la presidencia personal (carente de vínculos políticos con el Congreso) acentuó la separación entre los poderes y terminó en una dirección casi exclusivamente retórica. Con Bush hijo -el único nuevo regime builder-el reordenamiento de las instituciones se produjo como consecuencia de las amenazas externas. Además de conseguir internamente la disciplina de su partido, el Congreso le delegó su facultad de declarar la guerra, produciéndose así un nuevo régimen: la presidencia imperial, es decir, la presidencialización de todo el sistema de gobierno. Sin embargo, en 2006, ante los fracasos de su política internacional y doméstica -los demócratas ganaron ambas cámaras- "el estilo unilateral de la presidencia debió someterse a las restricciones políticas y constitucionales propias del sistema político estadounidense" (133), y la victoria de Obama en 2008 confirmó que el "régimen" neoconservador era en realidad frágil. Como se ve, el análisis de los últimos años hace que el argumento pierda claridad: no queda claro por qué un nuevo "régimen" dura sólo la mitad de una misma presidencia.

El capítulo 5 lleva a Europa. Allí la discusión no se dio sobre la función del líder sino sobre el gobierno de partido. En la primera fase del debate (fines de los $60 \mathrm{~s}$ y 70s) Rose postuló que el verdadero "gobierno de partido" se debía a programas detallados y miembros de los partidos en puestos gubernamentales importantes. Pero en ese momento empezaban a afirmarse los líderes, por lo que en la segunda fase del debate (80s) se elaboró un modelo de partido entendido como un conjunto de individuos (Katz) y al gobierno de partido como la acumulación de poder en el ejecutivo. Sin embargo, se impuso una estrategia de acción basada en líderes entendidos como actores individuales (y no como representantes de actores colectivos) que consideraron más racional enfatizar su persona que su partido, tanto en la campaña como en el gobierno. Pero cuando el debate alcanzaba su mayor sofisticación, los partidos europeos comenzaron a decaer (en número de afiliados y en identificación de los votantes), lo que subrayó el auge de los líderes. Los partidos reaccionaron a su decadencia reforzando su presencia en las instituciones (formando carteles) y democratizándose (básicamente a través de elecciones primarias). Así, en la tercera fase del debate (fines de los 80s) sí empieza a haber reflexiones sobre los líderes de gobierno en Europa, pero que en general no contemplan las diferencias de funcionamiento institucional entre los casos. "Sin su espíritu ideológico, enfrentando un electorado que no confía en ellos, y preocupados por preservar su control de los recursos públicos, los partidos han terminado por hacerse caracterizar por sus líderes" (155).

El capítulo 6 describe las características del éxito de los líderes en contextos institucionales que favorecen el gobierno de los partidos. Los medios de comunicación europeos personalizaron la política electoral y presidencializaron la acción de los ejecutivos. Pero todo ello no supone la norteamericanización de la política sino una consecuencia de las condiciones más amplias que estructuran el proceso político: la decadencia de la organización partidaria y la formación de nuevas divisiones y problemáticas en la agenda, fruto a su vez de profundas 
mutaciones económicas, tecnológicas y culturales. Por eso se redefinió la división izquierda-derecha, surgieron actores que no recurren a la mediación partidaria, y hay conflictos cambiantes sobre temas específicos que conviven con los conflictos tradicionales de clase y religión.

De esta manera, a una primera fase del gobierno del líder (caracterizada por jefes partidarios de los 70s que se personalizaban en los 80s, como Mitterrand, Thatcher y Craxi), siguió una segunda fase de líderes outsiders al establishment partidario, transformadores - tanto de las políticas de sus partidos como de la organización del ejecutivo-, y maximizadores de sus recursos personales: Blair redefinió la identidad del partido, basó su autoridad política en aspectos personales y manejó el gobierno con sus propias convicciones más que con el consenso del partido; Berlusconi creó un partido nuevo a su servicio, personalizó la política y promovió una nueva hegemonía cultural en los medios; y Sarkozy derrotó a la elite de su partido, rompió tradiciones nombrando ministros opositores y cultivó un vínculo personal con la opinión pública. En todos los casos la política se transformó en espectáculo como una estrategia para neutralizar resistencias partidarias e institucionales. Sin embargo, las estrategias de personalización (relación directa con los electores) tuvieron resistencias: salvo en el caso de Forza Italia, los partidos no se convirtieron en estructuras al servicio del líder, y las instituciones parlamentaristas y semipresidencialistas siguieron exigiendo la acción de actores colectivos como los partidos y las mayorías parlamentarias. El clima institucional europeo continúa siendo desfavorable para los gobiernos personales: si bien no puede evitar que surjan, puede obstaculizar su consolidación.

La tercera parte del libro explora los posibles desarrollos del gobierno del líder. El capítulo 7 se ocupa de las condiciones externas que favorecen al liderazgo. En efecto, en Estados Unidos, la Segunda Guerra Mundial y la Guerra Fría reforzaron el predominio del presidente ante la necesidad de tener una política exterior de alcance global. Fabbrini adhiere a la vieja tesis de que cuanto más expuesto internacionalmente está un país, tanto más se centraliza su proceso de toma de decisiones, sobre todo si tiene un conflicto crucial. De allí que con el fin de la Guerra Fría tuvo una política exterior sostenida más por la diplomacia y el comercio que por el poderío nuclear, y no hubo primacía presidencial sino prácticas decisionales más colegiadas. Sin embargo se fue desarrollando una visión unipolar neoconservadora que exigía la preeminencia decisional interna del presidente para enfrentar rápida y eficazmente la nueva amenaza de los weapon states con capacidad de destrucción masiva. Bush hijo creó una nueva presidencia imperial aplicando la teoría de la independencia del ejecutivo frente al Congreso, según la cual el presidente, en tanto jefe militar, tiene prerrogativas funcionales adicionales a sus responsabilidades constitucionales. En la Europa posbélica, algunos países concentraron y otros descentralizaron los poderes decisionales, y más tarde, el proceso de integración favoreció a los ejecutivos racionalizando los procesos decisionales internos y aumentando su visibilidad personal.

El capítulo 8 señala las condiciones institucionales que favorecen el gobierno del líder o del partido, ya que no existe un sistema de gobierno que maximice el 
rendimiento de ambos al mismo tiempo. Aunque los partidos están en decadencia y los líderes en ascenso, ambos son necesarios y sus funciones se maximizan si los dos están presentes. La tarea del líder es darle un objetivo a la acción del gobierno: sólo un individuo puede dar voz a las exigencias sociales difusas, un sentimiento de pertenencia a la ciudadanía y orientar la marcha del país. Sin el líder, que es una fuente de cambios, viene el estancamiento. La tarea del partido es concretar un programa de políticas públicas: sólo un actor colectivo puede asegurar la coherencia de las políticas del gobierno, garantizar su coordinación y supervisar su implementación por parte de la administración estatal. Sin partido, que es una fuente de estabilidad, viene el estancamiento. Tanto en Estados Unidos como en Europa, los debates y las reformas orientadas a encontrar la eficacia del gobierno han buscado una solución al problema de cómo vincular al líder con un equipo partidario, y a ambos con una mayoría parlamentaria. Ahora bien, un buen gobierno no sólo es eficaz, sino también controlado. El crecimiento del líder requiere un adecuado contrapeso. En Estados Unidos lo es el Parlamento, y en Europa la oposición. Sin embargo, esos controles han demostrado ser insuficientes. Hay que ampliar los controles adicionales del poder judicial y la opinión pública (medios y periodistas) para controlar sin debilitar.

En definitiva, el libro es fructífero al abordar con seriedad y sistematicidad un tema resbaladizo para la Ciencia Política, y al mostrar cómo el ascenso de los líderes gubernamentales se debe a razones estructurales. Pero es más que nada un libro sobre poderes ejecutivos comparados, y por lo tanto no es muy original en el enfoque teórico ni en la utilización de las variables, además de contener algunos argumentos poco convincentes. Es una buena aproximación al tema del liderazgo, pero no aporta mucho al especialista. Sí, en cambio, es útil académica y políticamente la conclusión de que la capacidad de gobierno depende simultáneamente de a) un líder capaz de orientar la acción de gobierno y satisfacer las expectativas de los ciudadanos; b) un partido en condiciones de gestionar el diseño, la coordinación y la implementación de las políticas públicas; y c) un ejercicio del poder ejecutivo que se reconozca como un recurso para afrontar una multiplicidad de problemas pero a la vez como una amenaza si se abusa de él. 